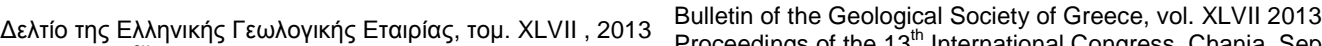

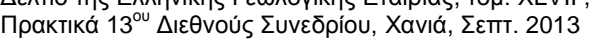
2013

\title{
RELATIONSHIP BETWEEN PHOSPHATES MINERALOGY AND MINERAL PROCESSING - THE CASE OF GREECE
}

\author{
Anastassakis G. \\ National Technical University of Athens (NTUA), School of Mining Engineering and Metallurgy \\ ganastas@metal.ntua.gr
}

\begin{abstract}
Phosphorus is one of the most important elements for life and growth of plants, animals and humans. Its absence or depletion from the soil necessitates their addition in the form of fertilizers. The only realistic source of elemental phosphorus and phosphoric fertilizers on commercial scale is phosphate rock. The importance of phosphate rocks becomes greater by taking into account that phosphorus can't be obtained by recycling processes as well as that there are no substitutes for it in agriculture.

In most cases, phosphate deposits have to be processed in order to meet the commercial requirements. In the current paper, it is presented the various forms of phosphate deposits, the participating minerals in each case and the effect of mineralogical composition on the beneficiation method applied. Finally, details on the phosphate deposits of Greece are presented, their mineralogy, and the possibility of their beneficiation.

Key words: Phosphate minerals, phosphate beneficiation methods, Greek phosphate deposits.
\end{abstract}

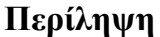

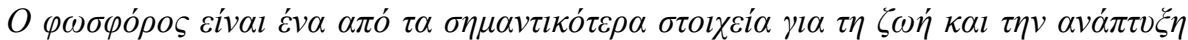

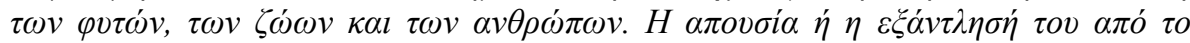

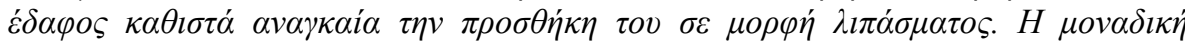

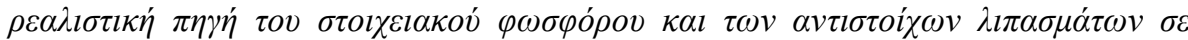

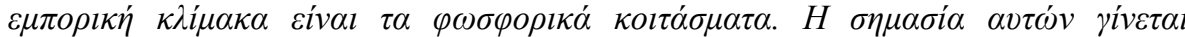

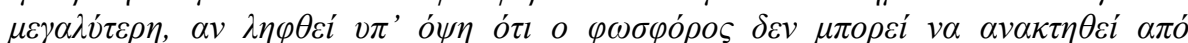

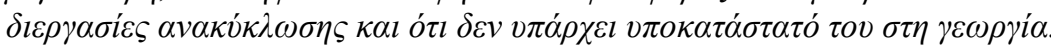

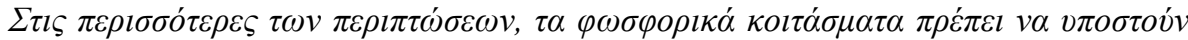

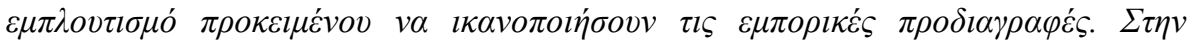

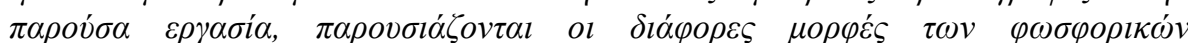

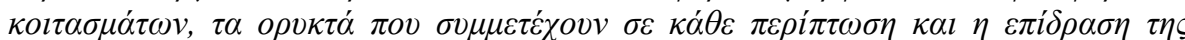

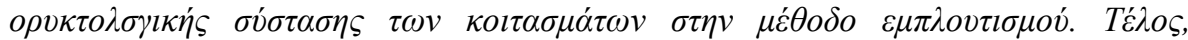

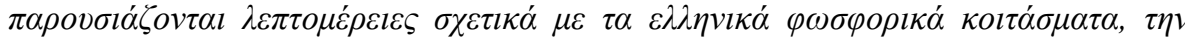

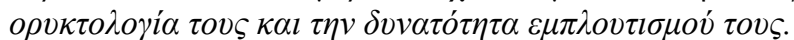

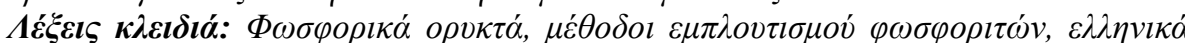

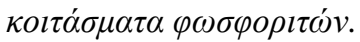

$\underline{\text { XLVII. No } 3-1609}$ 


\section{Introduction}

Phosphorus, along with potassium and nitrogen, is a very essential element in the agricultural and husbandry sectors as it is the basis for the production of fertilizers and animal stock feed. In case of phosphorus absence or depletion from soil, it must be added in the form of fertilizer. Phosphate rock is the only commercially feasible source for the production of phosphorus fertilizers and elemental phosphorus. The significance of phosphate rock becomes more intensive by taking into account that phosphorus can't be obtained from recycling processes and it can't be substituted in agricultural uses.

The term "phosphate rock" is globally accepted to describe any naturally occurring geological material that contains one or more phosphate minerals suitable for commercial use. This term is a general one as it is referred both to unprocessed rock and phosphate concentrates (Notholt and Highley, 1986). Economic recovery of phosphates is limited to the naturally concentrated mineral deposits. In case of some high-grade phosphate rocks, they are used as mined; in most cases, the deposits are of low-grade and they have to be concentrated in order to be economically utilized. Most of the world phosphate rock annually mined is consumed in phosphate fertilizers production.

Phosphate deposits are distributed worldwide but unevenly. The phosphate-rock producing countries are amounted to more than 30 but only four of them (with descending order China, USA, Morocco, and Russia) produced about $75 \%$ of the total production in 2012 (Jasinski, 2013). Studies regarding reserves and resources tonnage are widely varied (Fantel at al, 1984; Cathcart, 1984; Cooper and Manderson, 1984). The global proved reserves vary between 15 and 70 billions metric tons (Mt), the possible are double while the probable reserves are huge. World resources of phosphate rock are more than 300 billion tons (Jasinski, 2013). The market demands during the last 20 years are on average 150 millions Mt per year (UNEP, 2001). Obviously, whatever the tonnage of the proved reserves is, the existing proved reserves are efficient to cover the global demands for a long time under the current rate of production and market conditions. Identified and undiscovered resources worldwide are estimated to be several times greater than the present reserves. The various types of phosphate rock deposits as well as wide variations in $\mathrm{P}_{2} \mathrm{O}_{5}$ content create difficulties in accurately estimating reserves. The accurate tonnage estimates of reserves can not be made without systematic and extensive prospecting. Hence, the reserve and resource estimates subject to considerable change as exploration work increases the level of knowledge.

\section{Phosphate Rocks}

\subsection{Types}

Phosphate rocks appear extensive discrepancies regarding origin, structure, mineralogical composition and quality.

According to their origin, phosphate rocks are classified into sedimentary (or marine), igneous and guano. Most of the world's phosphate rock production (about 75\%) is from sedimentary deposits, $23 \%$ from igneous origin deposits and the remainder from guano. Sedimentary deposits are classified into autochthonous and heterochthonous while autochthonous are further divided into unaltered and altered.

Slightly different is the division proposed by van Straaten (2002), according which phosphate deposits are classified into the following five major types: marine, igneous, metamorphic, biogenic, and weathered. Metamorphic phosphate rocks derive from sedimentary and igneous phosphate rocks that have been subjected to extremely deep burial, where conditions of high pressure and perhaps shearing forces and/or heat prevail (van Kauwenbergh, 2010).

The most important producing countries of igneous origin phosphate rock are: Russia (in Cola Peninsula), South Africa (Palabora Complex), Zambia, Zimbabwe, Brazil (in Araxa and Jacuperanga), Finland and Sweden (Notholt, 1984). Igneous phosphate ores are often of low grade

$\underline{\text { XLVII, No } 3-1610}$ 
(less than $5 \% \mathrm{P}_{2} \mathrm{O}_{5}$ ), but can be upgraded to high-grade products (from about $35 \%$ to over $40 \%$ $\mathrm{P}_{2} \mathrm{O}_{5}$ ).

Sedimentary deposits (often called phosphorites) are the most important phosphorus raw material sources. Sedimentary phosphate rocks have been formed throughout the geological time scale. Most of them were apparently formed in offshore marine conditions on continental shelves. Sedimentary deposits exhibit a wide range of chemical compositions and great variations in physical form. The most desirable sedimentary phosphate rocks contain distinct phosphate particles that can be separated from the unwanted gangue minerals. They are much more widespread than the igneous ones and usually of higher content. Sedimentary deposits are defined in certain phosphate-bearing regions and countries, such as USA (Florida, North Carolina, Tennessee, Idaho, Montana, Utah, Wyoming etc.), Northern and Western Africa countries (Morocco, Tunisia, Algeria, Western Sahara, Togo etc.), Middle East (Jordan, Israel), China, Vietnam, Australia, Russia etc. Insular deposits, a type of sedimentary deposit associated with oceanic islands (such as Nauru and Christmas Island), have been an important source of phosphate rock for more than 100 years; however, most of these deposits have been totally depleted or have short projected remaining lifetimes (van Kauwenbergh, 2010).

Finally, guano deposits are limited and mainly located on the western Pacific islands of South America.

\subsection{Mineralogy}

The type of phosphate rock highly influences mineralogy, chemistry, texture and the concomitant gangue minerals. While the known phosphate minerals are amounted to more than two hundreds, the group of apatite is the main mineral found in phosphate deposits (van Straaten, 2002). Several cycles of deposition and reworking may have concentrated the phosphate, and weathering may have removed most of the carbonates from the near-the-surface portions of the deposits. Some igneous phosphate deposits, such as the Kola deposit in Russia, are hard-rock deposits; apatite crystals are found within a hard crystalline fabric of other igneous minerals. With intense weathering, the fabric of igneous phosphate rocks can be destroyed; soft soil-like residual deposits are produced. Sedimentary phosphate rocks can range from loose unconsolidated materials, to weakly cemented materials, to highly indurated rocks (van Kauwenbergh, 2010). Calciumphosphates of the apatite group are mainly found in primary environments (in sedimentary, metamorphic and igneous rocks) but also in weathering environments. Other phosphates include minerals of the crandallite group, as well as variscite and strengite, which are $\mathrm{Fe}$ - and $\mathrm{Al}$ containing phosphates principally found in secondary weathering environments (van Straaten, 2002).

The minerals prevailing in igneous phosphate rocks are mainly those of apatite group, with the general formula $\mathrm{Ca}_{10}\left(\mathrm{PO}_{4}\right)_{6} \mathrm{X}_{2}(\mathrm{X}$ is $\mathrm{F}, \mathrm{Cl}$ or $\mathrm{OH}$ anion). Due to its structure, apatite is subjected to extended substitutions. More specifically $\mathrm{Ca}^{2+}$ can be substituted by a variety of mono- or divalent cations, rare earth elements etc., $\mathrm{PO}_{4}{ }^{3-}$ is substituted by a variety of tri- or divalent radicals, such as $\mathrm{BO}_{3}{ }^{3-}, \mathrm{VO}_{4}{ }^{3-}, \mathrm{SiO}_{4}{ }^{3-}, \mathrm{AsO}_{4}{ }^{3-}, \mathrm{CrO}_{4}{ }^{3-}, \mathrm{CO}_{3}{ }^{2-}+\mathrm{F}^{-}$etc., and each one of the anions $\mathrm{F}^{-}, \mathrm{Cl}^{-}$and $\mathrm{OH}^{-}$can be substituted by the other two.

Primary igneous deposits owe their origin to the solidification of magma. They are associated with intrusive plutonic rocks, whose distinctive structure (e.g. high crystallinity) and mineral composition result from crystallization under conditions of slow cooling and often at considerable depth. Accordingly, the most common minerals associated with apatite are nepheline-syenites, carbonatite complexes, micas, pyroxenites, amphiboles, magnetite and other iron oxides, titanium minerals, olivine, feldspars, vermiculite etc.

In sedimentary origin deposits, the phosphate minerals prevailing are those of carbonate fluorapatite group or francolite. Some authors use the term "collophane" instead of francolite 
although the term "collophane" is referred to the structure of the phosphate rock denoting the micro- and cryptocrystalline apatite occurring in sedimentary rocks.

Francolite group minerals are described by the general formula (Abouzeid et al, 1980)

$$
\mathrm{Ca}_{10-\mathrm{a}-\mathrm{b}} \mathrm{Na}_{\mathrm{a}} \mathrm{Mg}_{\mathrm{b}}\left(\mathrm{PO}_{4}\right)_{6-\mathrm{x}}\left(\mathrm{CO}_{3}\right)_{\mathrm{x}} \mathrm{F}_{\mathrm{y}} \mathrm{F}_{2}
$$

where $\mathrm{x}$ is the extension of substitution of $\mathrm{PO}_{4}{ }^{3-}$ by $\left(\mathrm{CO}_{3}{ }^{2-}, \mathrm{F}\right)$. For commercial phosphate rocks $\mathrm{x}$ $=0-1.5$. Also, for electroneutrality to be maintained the following relationship must be in force $\mathrm{a}=$ $\mathrm{x}-\mathrm{y}$. Experimentally has been found that $\mathrm{y}=0.4 \mathrm{x}$ and $\mathrm{b}=0.4 \mathrm{a}$. X-Rays analysis revealed that substitution of $\mathrm{PO}_{4}{ }^{3-}$ by $\left(\mathrm{CO}_{3}{ }^{2-}, \mathrm{F}^{-}\right)$causes changes to the lattice and crystal size with concomitant changes in crystal specific area and reactivity of francolite. The maximum amount of substitution ranges between 6 and $7 \% \mathrm{CO}_{2}$. Sedimentary phosphate rocks containing the most highly carbonate-substituted apatites can only be beneficiated to maximum grades of 33-34\% $\mathrm{P}_{2} \mathrm{O}_{5}$. Depending on the amount of carbonate substitution, the grade can increase to a maximum of about $42 \% \mathrm{P}_{2} \mathrm{O}_{5}$ for sedimentary apatites with essentially no substitution (van Kauwenbergh, 2010).

Gangue minerals in sedimentary phosphate rock mainly include quartz, calcite, dolomite, clays (smectite, palygorskite, kaolinite, sepiolite), shales, iron oxides, pyrite, barite, fluorite and organic material. Some phosphate minerals (wavellite, crandallite, variscite) are also included in gangue.

Marketable phosphate rock is graded according to its content in tricalcium phosphate (64-77\%) or $\mathrm{P}_{2} \mathrm{O}_{5}$ but the content in various impurities is equally important. Deleterious minerals such as calcite, dolomite, iron and aluminum oxides must not exceed a certain percentage.

\section{Overview of Beneficiation Methods}

Theoretically, processing methods separate efficiently phosphate minerals from gangue for almost all the combinations of minerals. Restrictions are posed as far as it concerns the cost of the processing, given that phosphate rock concentrates are of relatively low value.

Flotation is applied almost exclusively to separate apatite from the other minerals in igneous phosphate rocks using various combinations of reagents (Guimaraes et al, 2005). Commercial grade of the concentrate is achieved through a series of rougher, cleaning and scavenging stages. In addition to flotation, processing of igneous rocks may also include washing, desliming, and magnetic separation depending on the nature of the gangue minerals (Woodrooffe, 1972; Anonymous, 1986).

Various separation methods and flow sheets are applied to separate phosphate from gangue minerals in sedimentary rocks as described in the following paragraphs (Anastassakis, 1989).

- If the gangue minerals is rich in organic material, iron minerals and sulfides, separation of phosphate matter is based on low-temperature roasting $\left(400-600{ }^{\circ} \mathrm{C}\right)$ combined with dry magnetic separation (Cohen and Hammoud, 1979). In addition, when dolomite and quartz also participate as gangue minerals, then high-intensity electrostatic separation is also applied (Hammoud et al, 1985); in case of ferriferous dolomite high gradient magnetic separation is applied (Blazy and Jdid, 1997).

- The simplest separation is achieved in high grade deposits (content in P2O5 more than $25 \%$ ) with silica and/ or clays as gangue minerals. Due to the difference in hardness between phosphate and silica, a commercial product is achieved with simple crushing and dry or wet screening (Anonymous, 1986).

- In most commercial applications, gangue is comprised mostly of silica and argillaceous minerals (clays, shale etc.). Argillaceous material usually serves as binding material of phosphate pebbles. Such a typical example is the phosphatic basins of southern United States. The formations of Florida-North Carolina represent more than $80 \%$ of the U.S. production. Phosphate ore is slurried in the processing plant and phosphate particles are subse-

$\underline{\text { XLVII, No } 3-1612}$ 
quently separated from the waste sand and clays. Beneficiation of the ore is accomplished by washing and flotation (Raden, 1979).

- After removing the coarse particles $(+1.5 \mathrm{~mm})$ and the fine ones $(-0.1 \mathrm{~mm})$ by washing, the fraction with particles size $-1.5+0.1 \mathrm{~mm}$ is fed to the flotation plant. This product is mainly composed of phosphate particles and silica sand. The coarse fraction $(-1.5+0.5 \mathrm{~mm})$ is separated by agglomerate-skin flotation (Hoppe, 1976; Moudgil and Barnett, 1979). The phosphate material in the finer fraction $(-0.5+0.1 \mathrm{~mm})$ is separated from silica sand by rougher and cleaning flotation processing. These circuits operate in parallel while at least two plants in Florida operate flotation without separating circuits for coarse and fine fraction (Custred et al, 1975).

- For phosphate deposits with a higher content, a single flotation stage is required, usually anionic, with fatty acid collectors.

- A serious problem in phosphate processing is the presence of dolomite as gangue mineral. Deposits of low $\mathrm{MgO}$ content had been exploited in Florida and western phosphate fields of USA up to now. The depletion of the low $\mathrm{MgO}$ content deposits necessitates the phosphate industry to process deposits with dolomitic higher content of impurities. Consequently, efficient processing techniques have to be set to lower the $\mathrm{MgO}$ content of the concentrates below $1 \%$, which is the limit for commercial phosphate concentrates. Experimental results show that a noticeable part of dolomite is removed by screening for particle size $+6 \mathrm{~mm}$ and in the light product of heavy media separation for particle size 1-6 mm (Baumann and Snow, 1980; Lawver et al, 1980; Rule and Daellenbach, 1985). The sink product is processed by double flotation: a) anionic with fatty acid emulsion and H2SiF6 as phosphate depressant and b) subsequent cationic flotation of the tailing for silica to be removed, using a mixture of amine with fuel oil or kerosene as collector at slightly acidic $\mathrm{pH}$.

- Approximately, two thirds of the phosphate world deposits have carbonate gangue minerals. Although much effort has been devoted to the separation of carbonates from phosphates, the results are not satisfactory yet because of the similar properties and response to the various physical and physicochemical methods. Unaltered phosphate deposits of low grade (P2O5 less than 20\%) with calcite as gangue mineral seem to be not amenable to separation on industrial scale despite some encouraging experimental results on lab scale (Woodrooffe, 1972; Anastassakis, 1989).

- Low-grade phosphate rocks (10-12\% P2O5), rich in carbonates, have been attempted to be beneficiated with dilute organic acids, such as acetic, citric or formic acid. Among them dilute acetic acid seems to be the most promising agent (Economou and Vaimakis, 1997; Sengul, 2006).

- For phosphate deposits with P2O5 content higher than $20 \%$ and with calcite gangue, calcination followed by slaking with water has been tested successfully (Good, 1976; Özer, 2003). The limited application of this process until now is due to its high energy cost. This process is not applied for relatively increased silica content of the ore.

From the above mentioned overview, it derives that phosphate ores show a wide diversity in the composition of their gangue minerals. Their beneficiation can be achieved by various processes, depending upon the liberation size of phosphate from its associated gangue minerals. Different simple or complex combinations of the following processes may be used: crushing, grinding, screening, washing, heavy media separation, flotation, roasting, acetic acid leaching, and calcination. Given that the value of phosphate concentrates is relatively low, cost and metallurgical results are expected to determine the most proper process. 


\section{Phosphate Resources of Greece}

\subsection{Types - Characteristics}

Phosphate deposits of Greece are located in Epirus area. They are of sedimentary origin and belong to the Mediterranean province of marine sedimentary deposits along with the deposits of northern Africa, south-eastern Turkey, and Albania. From geo-tectonic point of view, these deposits belong to the central Ionian Zone. In this zone, two types of phosphate deposits are encountered: the compact type (non-weathered) and the weathered.

The weathered deposits are located in the Drymon (Preveza) area; their reserves are limited to approximately $6 \mathrm{Mt}$, which are considered very limited in comparison to those of the compact type. The average content of these deposits varies between $15 \%$ and $23 \% \mathrm{P}_{2} \mathrm{O}_{5}$ with the major gangue mineral being chert $\left(18-40 \% \mathrm{SiO}_{2}\right)$ and, in lesser extend, limestone, iron minerals and clays.

The non-weathered deposits are located within a zone at the eastern part of the Central Ionian Zone, which is extended to a width of about $15 \mathrm{~km}$ and a length starting from Aitoloakarnania area to the Albanian borders. These phosphate rocks are characterized as phosphate limestone, because their content in $\mathrm{P}_{2} \mathrm{O}_{5}$ is, generally, less than $19.5 \%$ (Skounakis, 1979).

The phosphate limestone of Epirous area is formed as a stratigraphic horizon at the contact between Vigla limestone and limestone of Upper Senonian. It is characterized by a thin-layered structure with alternating layers of phosphate limestone, chert, and limestone. The thickness of the phosphate horizon varies from $2 \mathrm{~m}$ to $12 \mathrm{~m}$. On average, a thickness of $6-8 \mathrm{~m}$ can be considered that is maintained constant in a relatively extended area. The reserves of these deposits have not been precisely estimated. Based on the data of geological survey, they are estimated to be very large.

The $\mathrm{P}_{2} \mathrm{O}_{5}$ content of the deposits broadly varies both between the deposits and within each deposit. There have been detected deposits with such high a $\mathrm{P}_{2} \mathrm{O}_{5}$ content as $28-33 \%$ but with limited reserves; also, deposits with very low content such as $7.6 \% \mathrm{P}_{2} \mathrm{O}_{5}$; the great majority of the deposits has a $\mathrm{P}_{2} \mathrm{O}_{5}$ content from 8 to $16 \% \mathrm{P}_{2} \mathrm{O}_{5}$ while the reserves are more than considerable (Pitsikas, 1981). As regards the content variation in the deposits themselves, it has been confirmed that the high content material is located in the lower part of the phosphate horizon having a thickness of about $2-3 \mathrm{~m}$; in the upper part, the content is significantly reduced.

Chert is encountered in the phosphate horizon as layers (thickness $5-20 \mathrm{~cm}$ ) alternating with phosphate and calcitic material; its participation in the phosphate horizon varies from area to area. Sometimes, low-grade phosphate material $\left(1.5-2 \% \mathrm{P}_{2} \mathrm{O}_{5}\right)$ is encountered in the chert layers.

The gangue limestone is encountered in the form of layers or beds (thickness $10-60 \mathrm{~cm}$ ), in white or sub-white colour, with Mn-dendrites encountered on the surface of all the layers.

The phosphate material appears in the phosphate horizon in one of the following types:

- Banded type. In this type the bands are of variable thickness $(0.5-4 \mathrm{~mm})$ and colour (from white-grey to deep brown). Gangue limestone or sparse phosphate material is intercalated between the phosphate bands. The more banded and the more intensive their colour is, the higher the $\mathrm{P} 2 \mathrm{O} 5$ content is.

- Porous type. In this type, phosphate limestone appears compact enough, without intercalations of gangue limestone, with grained structure and high content in P2O5.

- Weathered type. It derives from the compact type after having undergone secondary in situ enrichment due to the dissolution and removal of limestone because of rain water action. In some cases, the upper layers are weathered while the lower maintain their compact form.

\subsection{Mineralogy}

Extensive geochemical and mineralogical research on the Epirous phosphate rock has been carried out (Tsailas et al., 1980; Perdikatsis, 1991; Leventouri et al., 2000). The phosphate mineral 
confirmed for Epirous deposits is francolite with high degree of substitution $\mathrm{CO}_{3}{ }^{2-}$ and $\mathrm{F}^{-}$for $\mathrm{PO}_{4}{ }^{3-}$ with lattice cell dimensions $\mathrm{a}_{0}=9.32 \AA$ and $\mathrm{c}_{0}=6.896 \AA$ (Tsailas et al., 1980). According to the statistical standards, francolite mineral with $\mathrm{a}_{0}=9.32 \AA$ corresponds to the mineralogical formula

$$
\mathrm{Ca}_{9.51} \mathrm{Na}_{0.35} \mathrm{Mg}_{0.14}\left(\mathrm{PO}_{4}\right)_{4.74}\left(\mathrm{CO}_{3}\right)_{1.26} \mathrm{~F}_{2.5}
$$

Its theoretical content in $\mathrm{P}_{2} \mathrm{O}_{5}$ is $34.76 \%$.

In the phosphate bands of the rock, francolite aggregates form grains with size of a few micrometers. These very fine grains form compact phosphate concentrations, oolites, spherolites and phosphate nodules. Fine-grained calcite mass, of un-regular shape is encountered between the aforementioned phosphate formations. As regards the phosphate rock texture, it must be pointed out that francolite and calcite are very intimately connected. Liberation study reveals that francolite is liberated from calcite for such a low particle size as $-10 \mu \mathrm{m}$.

The major gangue mineral of the phosphate rock is calcite, and chert in lesser amount; iron oxides and Al-minerals (clays) are also encountered but at a very low percentage. Because of the low $\mathrm{P}_{2} \mathrm{O}_{5}$ content (12-13\%) and the corresponding high in $\mathrm{CaO}$ (approximately 50\%), the ratio $\mathrm{CaO}$ / $\mathrm{P}_{2} \mathrm{O}_{5}$ is 4.24 , which is considered very high in comparison to those rocks used for industrial purposes and have a corresponding ratio 1.6. The high ratio denotes that the sulfuric acid consumption is high and the process of $\mathrm{H}_{3} \mathrm{PO}_{4}$ or fertilizers production is not economic. Also, in the current case, the content of the rock in uranium or other rare elements is not significant to increase its value, e.g. 21-22 ppm U, 1270-2300 ppm Sr, 150-225 ppm Ti, 0-200 ppm La, 0-100 ppm Zr, 0-200 ppm Nb, up to 50 ppm W etc. (Tsailas et al., 1980).

\subsection{Beneficiation Results}

Weathered deposits of Greece have been tested to beneficiation. Tests carried out at pilot-plant scale showed that it is possible to obtain a phosphate concentrate with approximately $29-30 \% \mathrm{P}_{2} \mathrm{O}_{5}$, weight 52\% and $\mathrm{P}_{2} \mathrm{O}_{5}$ recovery $68 \%$ through sorting (Tsailas et al., 1978; Tsailas et al., 1981; Kaklamanis, 1983).

Given the texture of the unaltered phosphate rock of Epirus area and the very fine size that the rock has to be ground for complete liberation of phosphate matter from gangue minerals, the beneficiation was targeted either to obtain a preconcentrate or a concentrate, if possible.

Gravity separation methods were employed to examine the possibility to obtain a preconcentrate. Float-sink analysis revealed that it is possible to obtain a sink product with heavy liquid separation at sp. gr. 2.75, for the particle fraction $-3.35+0.075 \mu \mathrm{m}$. Depending on the size range of the feed, the sink product had $40-55 \%$ weight, $20-23 \% \mathrm{P}_{2} \mathrm{O}_{5}$, and $80-90 \% \mathrm{P}_{2} \mathrm{O}_{5}$ recovery. The theoretical results of heavy liquid tests were partially confirmed, when the separation was carried out in dense medium bath, either static or whirling, as it was not possible to obtain a concentrate having both satisfactory $\mathrm{P}_{2} \mathrm{O}_{5}$ content and recovery. More specifically:

- In static separation, the best results were obtained for the size fraction $+6.35 \mathrm{~mm}$ at a sp. gr. 2.61. The content of the sink product was $17.15 \%$ P2O5 (feed content $14.60 \%$ P2O5), its weight $67.18 \%$ of the dense medium feed, and the recovery in P2O5 was $79 \%$ approximately. Separation at a dense medium density 2.65 increases P2O5 content of the sink to $17.86 \%$ but reduces recovery to about $70 \%$. Taking into account the weight of the size fractions in the initial feed, recovery drops to the level of $21-23 \%$, which is very low.

- In cyclone whirling dense medium, the results are increased as regards P2O5 content but decreased as regards recovery. More specifically, for the particle fraction $-4+0.6 \mathrm{~mm}$, the content of the sink product was $20 \%$ P2O5, its weight $18-30 \%$ depending on the size range while the recovery in $\mathrm{P} 2 \mathrm{O} 5$ was approximately $40 \%$ of the cyclone feed. Taking into account the weight of the size fractions in the initial feed, recovery drops to about $15 \%$, which is very low. 
Flotation was extensively investigated as a potential separation method using a great variety of reagents but the results were not satisfactory because of the similar physicochemical properties of phosphate minerals and calcite.

In conclusion, phosphate rock processing of Epirus area doesn't seem easy, because of the similar behavior of phosphate and gangue minerals (especially calcite).

\section{Conclusions}

Phosphate rock is one of the most important mineral commodities as it is the only source of phosphorous, which is a substantial element for human beings, animal and plants. The mineralogical composition of the phosphate rocks is mainly determined by their origin and conditions of genesis. Separation of phosphate minerals from gangue is primarily achieved through washing and flotation procedures in sedimentary rocks while flotation is the major beneficiation method of igneous deposits.

In respect to the Greek territory, phosphate deposits have been discovered in Epirus area. The weathered type can be beneficiated and produce a commercial concentrate with $30 \% \mathrm{P}_{2} \mathrm{O}_{5}$ but its reserves are relatively limited. On the contrary, the non-weathered type has abundant reserves of low grade (in most cases $12-16 \% \mathrm{P}_{2} \mathrm{O}_{5}$ ) but the problem is focused on the difficulty to separate phosphate matter from gangue minerals (mostly calcite) due to their similar behaviour both to physical and physicochemical separation methods.

\section{References}

Abouzeid A.M., El Jallad I.S., and Orphy M.K. 1980. Calcareous phosphates and their calcined products, Minerals Sci. Engineering, 12(2), 73-83.

Anastassakis G.N. 1989. Contribution to the beneficiation of unaltered phosphate rock of Epirous area (Greece), PhD, National Technical Univ. of Athens, Dept. Mining Eng. and Metallurgy, 223pp.

Anonymous 1986. Phosphates: A review of processing techniques, World Mining Equipment, April, 40-43.

Baumann A.N. and Snow R.E. 1980. Processing techniques for separating MgO impurities from phosphate products, $2^{\text {nd }}$ Intern. Congress Phosphorous Compounds, Boston, April 1980, 269-280.

Blazy P. and Jdid E.A. 1997. Removal of ferriferous dolomite by magnetic separation from the Egyptian Abu Tartur phosphate ore, Int. J. Miner. Process., 49, 49-58.

Cathcart J.B. 1984. Sedimentary Phosphate deposits of the world: Present status and outlook for the future, In Phosphates: What prospects for growth?, Metal Bulletin Inc., New York, 942.

Cohen E. and Hammoud N.S. 1979. Low temperature roasting in ungrading the non-oxidized phosphorites of Abu-Tartur Plateau (Western Desert, Egypt), XIII Int. Mineral Process. Congress, Warsaw, 1979, 1828-1844.

Cooper C.D., and Manderson, M.C., 1984. Phosphate rock: The emerging world and regional supply and demand outlook into the late 1980's, In Phosphates: What prospects for growth?, Metal Bulletin Inc., New York, 214-226.

Custred V.K, Degner V.R., and Long E.W. 1975. Recent advance in coarse particle recovery utilizing large capacity flotation machines, Trans. SME-AIME, 258, 324-325.

Economou E.D. and Vaimakis T.C. 1997. Beneficiation of Greek calcareous phosphate ore using acetic acid solutions, Ind. Eng. Chem. Res., 36, 1491-1497.

Fantel R.J., Anstett T.F., Peterson G.R., Porter K.E. and Sullivan D.E. 1984. Phosphate rock availability: World, I.C. 8989, U.S. Bureau of Mines, 4-5, 11.

Good P.C 1976. Beneficiation of unaltered Indian calcareous phosphate rock by calcination and hydration, RI 8154, US Bureau of Mines, 1-17.

XLVII, No $3-1616$ 
Guimaraes R.C., Araujo A.C. and Peres A.E.C. 2005. Reagents in igneous phosphate ores flotation, Minerals Engineering, 18, 199-204.

Hammoud N.S., Khazback A.A. and El-Gemmizi M.A. 1985. Beneficiation of complex low-grade phosphorites of Abu Shegeila (Red Sea, Egypt), XV Intern. Miner. Process. Congress, Cannes, 1985, Vol. 3, 412-423.

Hoppe R. 1976. From matrix of fertilizers. Florida's phosphate industry girds to produce over 50 million t.p.y., Eng. Min. J., 177(9), 81-93.

Jasinski S.M. 2013. Phosphate rock, in Mineral Commodities Summaries, USGS, 118-119.

Kaklamanis N. 1983. Results on the operation of phosphate rock pilot-plant in April 1983, Report of the Institute of Geology and Mineral Exploration (Greece).

Lawver J.E., Raulerson J.D. and Cook C.C. 1980. New techniques in beneficiation of phosphate rock, Trans. SME - AIME, 268, 1787-1802.

Lenentouri Th., Chakoumakos B.C., Moghaddam H.Y. and Perdikatsis V., 2000. Structural studies of a carbonate fluorapatite from powder Neutron Diffraction data, Materials Science Forum, Vol. 321-324, 924-930.

Moudgil B.M. and Barnett D.H. 1979. Agglomeration-skin flotation of coarse phosphate rock, Mining Eng., 31(3), 283-289.

Notholt A.J.G. 1984. Igneous phosphate resources: Their growing contribution to world markets, In Phosphates: What prospects for growth?, Metal Bulletin Inc., New York, 43-58.

Notholt A.J.G. and Highley D.E. 1986. World phosphate resources, with particular reference to potential low-grade ores, Trans. Instn. Min. Metall. (Section B: Applied Earth Sci.), 95, A125-132.

Özer A.K. 2003. The characteristics of phosphate rock in a fluidized bed for the upgrading, $A d v$. Powder Technol., 14 (1), 33-42.

Perdikatsis V. 1991. X-Ray power diffraction study of francolite by the Rietveld method, Mat. Science Forum, Vol. 79-82, 809-814.

Pitsikas L. 1981. Reserves estimation of the phosphate deposit with compact structure of Kosmiras-Ioannina area with a content 10-14\% $\mathrm{P}_{2} \mathrm{O}_{5}$, Report of the Institute of Geology and Mineral Exploration (Greece).

Raden D.J. 1979. Current problems in beneficiation of phosphate fines, In P. Somasundaran and N. Arbiter (eds), Beneficiation of Mineral Fines - Problems and Research Needs, 79-93, AIME, 406 pp.

Rule A.R. and Daellenbach C.B. 1985. Beneficiation of complex phosphate ores containing carbonate and silica gangue, XV Intern. Mineral Processing Congress, Cannes, Vol. III, 380389.

Sengul H., Ozer A.K. and Gulaboglu M.S. 2006. Beneficiation of Mardin-Mazidagi (Turkey) calcareous phosphate rock using dilute acetic acid solutions, Chemical Engineering Journal, 122, 135-140.

Skounakis S. 1979. Contribution to the study of the genesis conditions of the phosphate deposits of western Greece. Thesis, University of Athens, Athens, $143 \mathrm{pp}$.

Tsailas D., Kalantzopoulos G., Kalatzis G. and Grossou-Valta M. 1978. Study on the possibility of amelorization of the altered phosphate rock of Drymon area for phosphoric acid production, Report of the Institute of Geology and Mineral Exploration (Greece).

Tsailas D., Grossou-Valta M., and Kalatzis G., 1980. Study on the possibility of amelorization of the unaltered phosphate rock of Epirous area, Report of the Institute of Geology and Mineral Exploration (Greece).

Tsailas D., Grossou-Valta M. and Kalatzis G. 1981. Amelorization of the altered phosphate rock of Epirous area, Report of the Institute of Geology and Mineral Exploration (Greece).

UNEP 2001. Environmental aspects of phosphate and potash mining, $61 \mathrm{pp}$.

Van Straaten P. 2002. Rocks for Crops: Agrominerals of sub-Saharan Africa, ICRAF, Nairobi, Kenya, 338pp.

Van Kauwenbergh S.J. 2010. World Phosphate Rock Reserves and Resources, IFDC, 60pp.

Woodrooffe H.M. 1972. Phosphate in the Kola Peninsula, USSR, Min. Eng., 24(12), pp. 54-56. 